\title{
An investigation of worn work roll materials used in the finishing stands of the hot strip mill for steel rolling
}

\author{
M. Nilsson ${ }^{1,2} *$, M. Olsson ${ }^{1,2}$ \\ ${ }^{1}$ Dalarna University, SE-791 88 Falun, Sweden. \\ ${ }^{2}$ Uppsala University: Ångström Laboratory, Box 534 SE-751 21, Sweden.
}

\begin{abstract}
The surface failure characteristics of different work roll materials, i.e. High Speed Steel, High Chromium Iron and Indefinite Chill Iron, used in the finishing stands of a hot strip mill have been investigated using stereo microscopy, 3D optical profilometry, scanning electron microscopy and energy dispersive X-ray spectroscopy. The results show that the surface failure mechanisms of work rolls for hot rolling are very complex, involving plastic deformation, abrasive wear, adhesive wear, mechanical and thermal induced cracking, material transfer and oxidation. Despite the differences in chemical composition and microstructure, the tribological response of the different work roll materials was found to be strongly dependent on the material microstructure and especially the presence and distribution of microstructural constituents, such as the different carbide phases and graphite (in the case of Indefinite Chill Iron). Cracking and chipping of the work roll surfaces, both having a negative impact on work roll wear, are strongly influenced by the presence of carbides, carbide networks and graphite in the work roll surface. Consequently, the amount of carbide forming elements as well as the manufacturing process must be controlled in order to obtain an optimised microstructure and a predictable wear rate.
\end{abstract}

Keywords: Work rolls, hot strip mill, surface failure, wear, cracking

*Corresponding author: Maria Nilsson (mnn@du.se).

\section{INTRODUCTION}

The finishing stands of a hot strip mill (HSM) are generally built up by six or seven pairs of work rolls. The conditions are severe with high temperature and pressure [1]. During rolling, any surface element on the work roll surface is alternately loaded and heated by the contacting hot steel and cooled by water. Consequently, high compressive and tensile stresses are generated at a frequency of the roll rotation resulting in mechanical and thermal surface fatigue. The rolls therefore demand high wear resistance and high impact toughness [2-3]. Wear of the work rolls occurs either relatively uniform on the contact surface or local in deeper wear bands. The uniform wear is mainly caused by abrasion in combination with thermal fatigue [3]. The most severe wear associated with banding is caused by thermomechanical fatigue of the roll surface [4]. Thermal fatigue induces the formation of cracks perpendicular to the roll surface [5-6]. According to Walmag et al [5] the length of these cracks can vary between 80 and $350 \mu \mathrm{m}$ depending on rolling conditions and are more frequent in stands 1-2. Contact fatigue cracks, which mainly occur in the last stands, are parallel to the surface and are a result of the high-pressure contact with the backup rolls [5].

In the finishing stands for steel rolling, mainly three different types of materials are used for the work rolls. High Speed Steel (HSS) and High Chromium Iron $(\mathrm{HCr})$ are used in the early stands and Indefinite Chill Iron (IC) in the last two or three stands. In HSS the hard carbides, such as $\mathrm{M}_{6} \mathrm{C}, \mathrm{M}_{2} \mathrm{C}, \mathrm{M}_{7} \mathrm{C}_{3}$ and $\mathrm{MC}$, are found in a more discontinuous network than those in $\mathrm{HCr}$ and IC [7]. The latter two have higher carbide content than HSS. $\mathrm{HCr}$ has carbides of $\mathrm{M}_{7} \mathrm{C}_{3}$ type while IC has carbides of $\mathrm{M}_{3} \mathrm{C}$ type as well as some graphite to ensure an appreciable lubricating effect [89]. Both IC and $\mathrm{HCr}$ rolls are nowadays reinforced by using other carbide formers, such as niobium, to form MC [9].

The development of HSS rolls has led to large improvements within hot rolling, such as higher wear resistance, better quality of the strip and extended rolling campaigns [1]. Park et al [10] as well as Ziehenberger and Windhager [11] have found the HSS 
rolls to have three to four times higher wear resistance than $\mathrm{HCr}$ rolls. The latter investigation found that the $\mathrm{HCr}$ rolls could be used 7,400 tons/mm while HSS rolls were used 22,800 tons $/ \mathrm{mm}$. To enhance the wear resistance of HSS even more, Hwang et al [2] recommend to increase the hardness of the hardened martensitic matrix and to form a large amount of hard carbides. Belzunce et al [8] mean that the high friction coefficient of HSS prevents their use in the last finishing stands of the mill, where strip temperature is lower, the rolling load is very high and the most important action is abrasive wear.

The scope of this work is to investigate the surface deterioration on both macro and micro level for HSS, $\mathrm{HCr}$ and IC HSM work roll materials used in the work rolls of the finishing stands.

\section{EXPERIMENTAL}

\subsection{Materials}

The work roll materials investigated in the present study cover High Speed Steel (HSS), Indefinite Chill Iron (IC) and High Chromium Iron (HCr) grades made by different producers, see Table 1 and Figure 1. The samples investigated were obtained from out of service work rolls used in the finishing stands at SSAB EMEA in Borlänge, Sweden. All samples, typically 30x20x10 $\mathrm{mm}$ in size, were cut out from the work rolls by using an angle grinder. Care was taken to assure that the sample, and especially the work roll surface, was not affected and contaminated by the grinding process.
Samples were taken from five HSS, seven IC and one $\mathrm{HCr}$ roll, respectively. The HSS work rolls had been used in stands 1, 2 and 4 for 8-215 km (375-5,664 tons). The IC work rolls had been used in stands 5-6 for 16-77 $\mathrm{km}$ (490-3,950 tons). The $\mathrm{HCr}$ roll had been used in lower stand 3 for $65 \mathrm{~km}$ (2,721 tons). The strip materials rolled are a mixture of high strength steel grades, see Table 1.

\subsection{Characterisation}

The macroscopic and microscopic characteristics of the worn work roll samples were characterised using an Olympus SZX 16 stereo microscope (SM), a Wyko NT9100 3D optical surface profilometer and a Zeiss Ultra 55 field emission gun scanning electron microscope (FEG-SEM) equipped with an Oxford INCA Energy Dispersive X-ray Spectroscopy (EDS) system.

Metallographic cross sections, perpendicular to the rolling direction, were obtained by conventional metallographic preparation procedures using $1 \mu \mathrm{m}$ diamond particles in the last polishing step. Micro hardness profiles of the subsurface material to a depth of $700 \mu \mathrm{m}$ were obtained by micro Vickers hardness indentation using a CSM Instruments Micro Combi Tester. Loading and unloading were performed for 30 $\mathrm{s}$, respectively, with a holding period of $15 \mathrm{~s}$ at the maximum load of $20 \mathrm{~g}$. By using the obtained indentation curves (load vs. indentation depth) the hardness were calculated according to Oliver-Pharr [12].

Table 1: Common ranges of the chemical composition of the work roll materials and the strip material.

\begin{tabular}{|l|l|l|l|l|l|l|l|}
\hline & $\% \mathrm{C}$ & $\% \mathrm{Si}$ & $\% \mathrm{Mn}$ & $\% \mathrm{Mo}$ & $\% \mathrm{Cr}$ & $\% \mathrm{Ni}$ & $\% \mathrm{~W}, \mathrm{~V}, \mathrm{Nb}, \mathrm{Ti}$ \\
\hline HSS & $1-2$ & $0.5-1$ & $0.5-1.5$ & $1-5$ & $3-7$ & $0.5-1.5$ & $2-8$ \\
\hline IC & $3-4$ & $0.5-1.5$ & $0.5-1.6$ & $0.2-1$ & $1.5-2.5$ & $4-5$ & $1-4$ \\
\hline HCr & $2-3$ & $0.6-1$ & $0.8-1.2$ & $1-1.5$ & $15-20$ & $1-1.5$ & $<0.5$ \\
\hline Strip material & $0.05-0.2$ & $0.1-0.6$ & $0.6-2$ & - & $0-1.3$ & - & $0-0.5$ \\
\hline
\end{tabular}
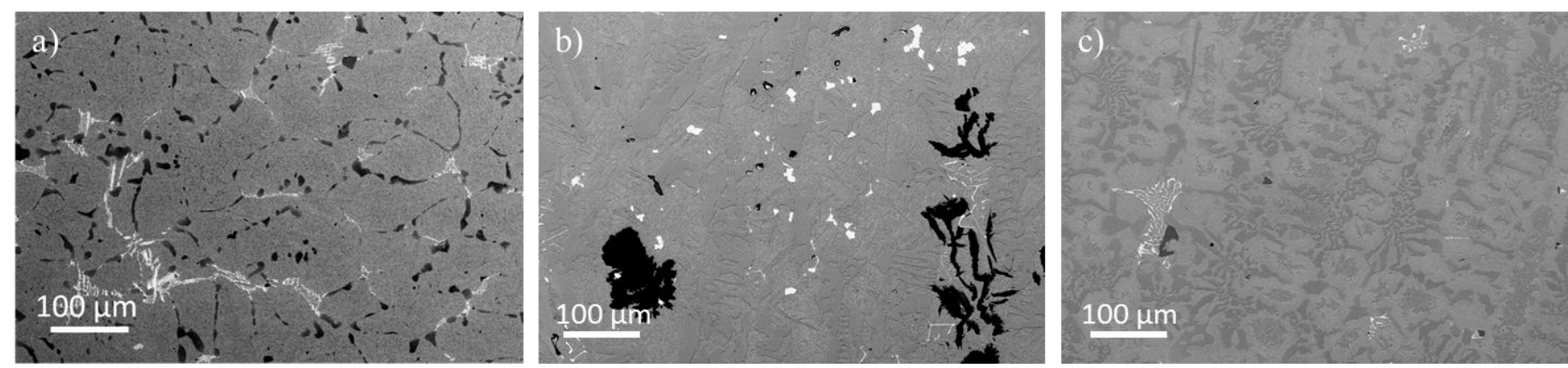

Figure 1: Microstructure of a) HSS, b) IC and c) HCr work roll material. 


\section{RESULTS}

\subsection{Macroscopic observations}

Figure 2 shows representative SM micrographs and 3D surface profilometry images of worn work roll surfaces representing the three different materials investigated. As can be seen, all worn surfaces show grooves in the rolling direction, indicating a combination of plastic deformation, abrasive and adhesive wear. Besides, the worn IC work roll show a high number of pits in the surface while the $\mathrm{HCr}$ work roll show a network of cracks in the surface. The latter work roll also shows a banded appearance with darker and brighter bands. Despite these differences, the mean $\mathrm{R}_{\mathrm{a}}$-value of the different work rolls investigated were all in the range 1.0-1.5 $\mu \mathrm{m}$.

Micro hardness profiles of the subsurface material show no hardness gradient from the surface and into the bulk material. The matrix hardness of the work roll materials was found to be in the range $680-800 \mathrm{HV}_{0.02}$, HSS being the hardest and IC being the softest.

\subsection{Microscopic observations}

\subsubsection{General surface failure mechanisms}

SEM and EDS analysis of the worn surface of the work rolls revealed that these are exposed to several surface failure mechanisms, i.e. plastic deformation, abrasive wear, adhesive wear, cracking, material transfer and oxidation. Figure 3 shows representative examples of worn work roll surfaces of the materials investigated. Of these, the worn HSS surfaces show the most pronounced grooving and the lowest tendency to material transfer, the worn IC surfaces the most pronounced pitting, and the worn $\mathrm{HCr}$ surfaces the most pronounced cracking as well as material transfer/surface oxidation tendency.

\subsubsection{Mechanical and thermal induced cracking}

Polished cross-sections of the worn work roll samples revealed that two different types of surface cracking can be distinguished, i.e. mechanical induced cracks (mainly propagating parallel to the surface) and thermal induced cracks (mainly propagating perpendicular to the surface), respectively. While mechanical cracks dominate in the IC work rolls, thermal cracks dominate in the HSS work rolls. A combination of mechanical and thermal cracks is to be seen in $\mathrm{HCr}$ work rolls. Representative micrographs are shown in Figure 4. In general, the cracks tend to propagate along the carbide networks by following the carbide-matrix interface, within the carbides or, in the case of the IC work rolls, in connection to the graphite phase, i.e. the material microstructure has a strong impact on the cracking tendency and morphology. The propagation depth of thermal cracks as well as the depth for mechanical induced cracks are for all work roll materials $100-150 \mu \mathrm{m}$.
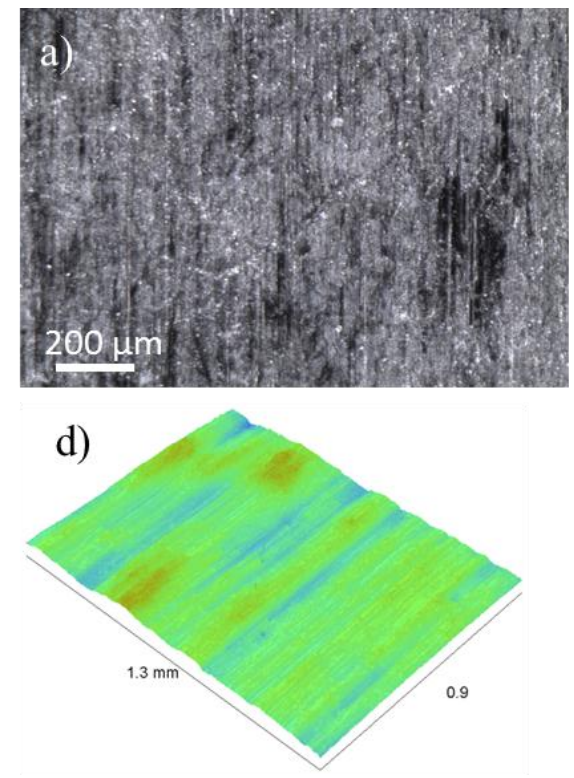
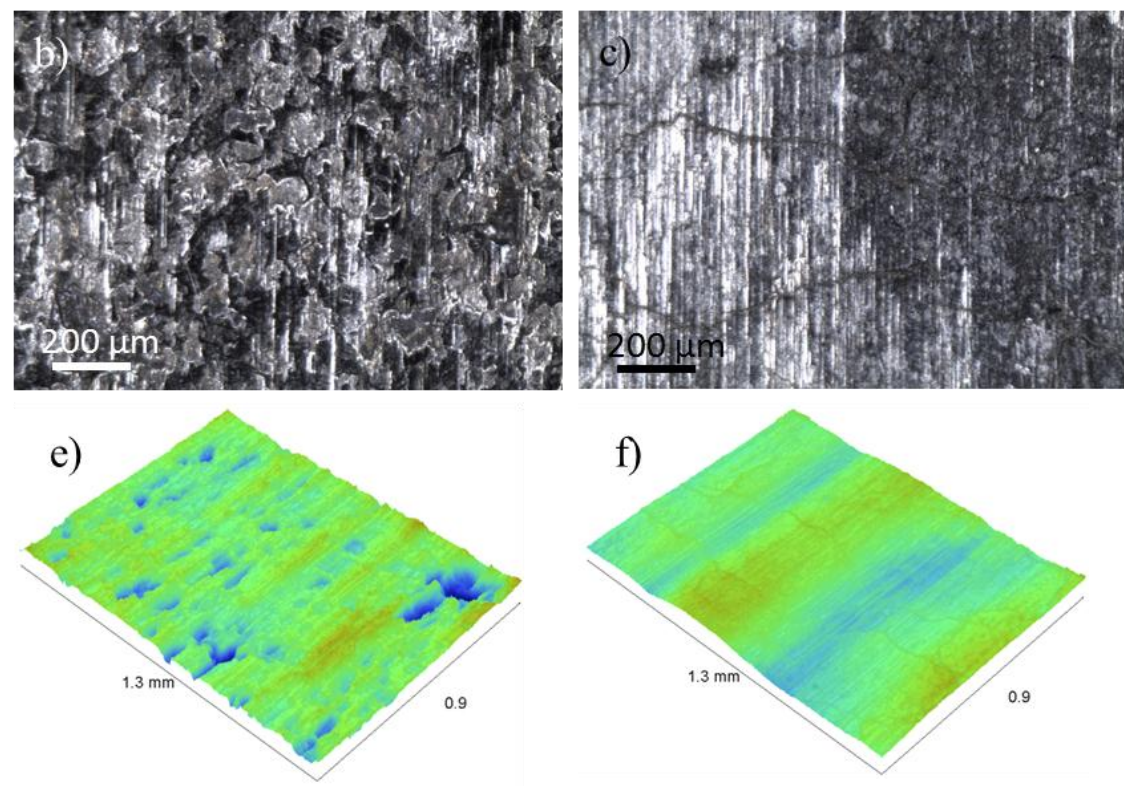

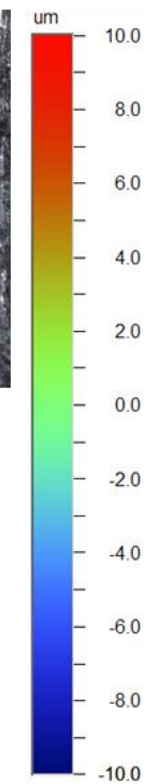

Figure 2: Stereo micrographs and 3D surface profilometry images (area $0.9 x 1.3 \mathrm{~mm}^{2}$ ) showing the worn surface morphology of $a, d) \mathrm{HSS}, \mathrm{b}, \mathrm{e}) \mathrm{IC}$ and $c, f) \mathrm{HCr}$ work rolls. 


\subsubsection{Chipping}

Chipping of small wear fragments is commonly observed in connection to the cracks in the close surface region. In general, two different types of chipping can be distinguished, see Figure 5, chipping of smaller carbide fragments due to cracking of individual carbides and chipping of somewhat larger fragments due to cracking along interconnecting carbide networks. While the former chipping mechanisms dominate for the IC material, both are seen to about the same extent in $\mathrm{HSS}$ and $\mathrm{HCr}$ materials.

\subsubsection{Work material pick-up and oxidation}

All worn work roll surfaces show a tendency to work (strip) material pick-up and surface oxidation. EDSanalysis shows that the surface oxide layer generally consists of oxidised work material being transferred to the work roll surface. For the HSS and $\mathrm{HCr}$ work rolls, the surface oxide is more or less continuous, covering larger areas, see Figures $\mathbf{6}$ a-b, while for the IC work rolls, the surface oxide is discontinuous and mainly located to the surface pits, see Figures 6 c-d. Besides, the oxide also shows a tendency to wedge and grow into the surface cracks, see Figures 6 a-b.
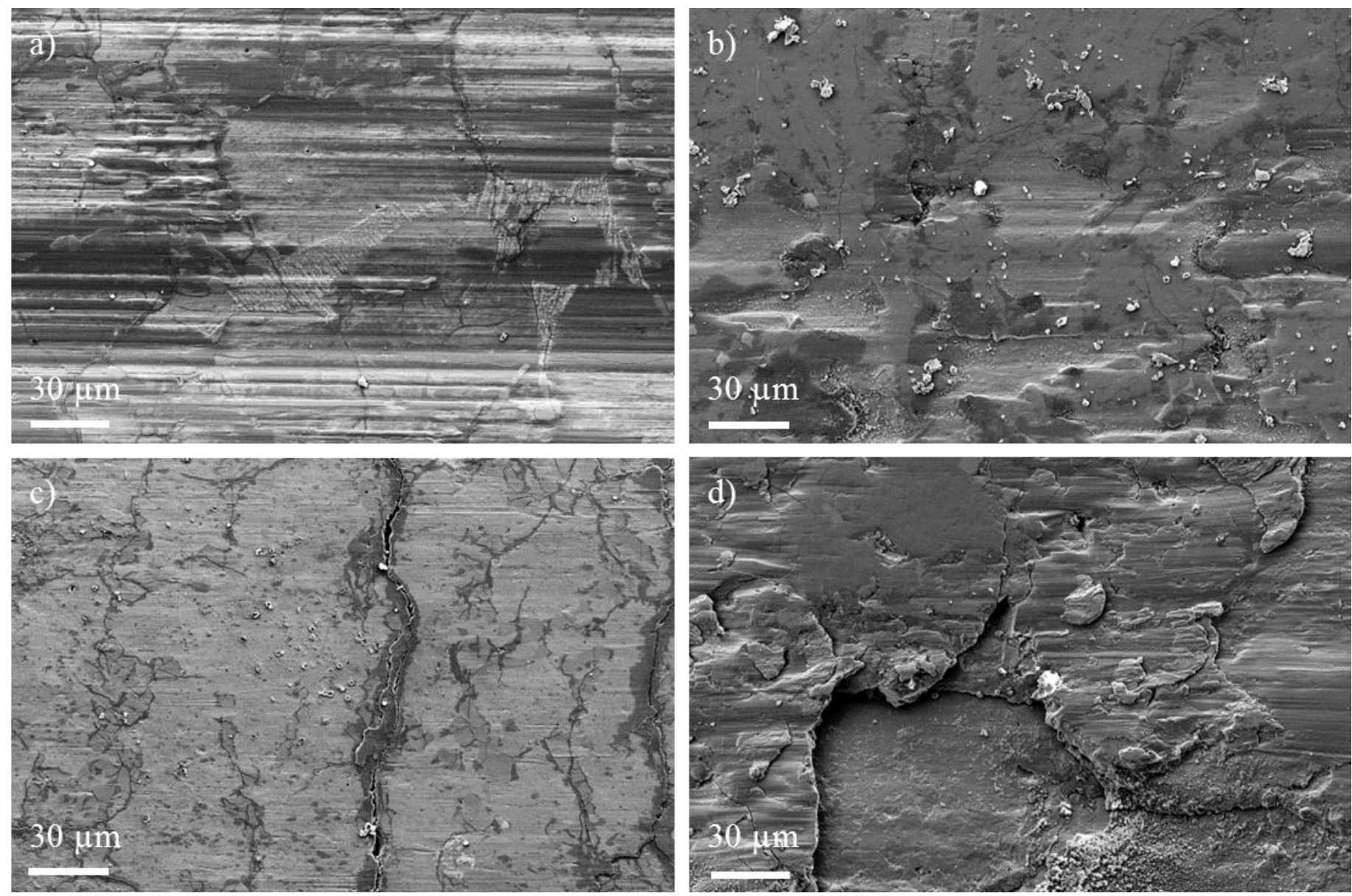

Figure 3: SEM micrographs of worn a) HSS, b) IC and c) and d) $\mathrm{HCr}$ work roll surfaces. Micrographs $c$ ) and d) correspond to the metal bright (c) and dark, oxidised (d) areas of the HCr work roll in Fig. 2 e).
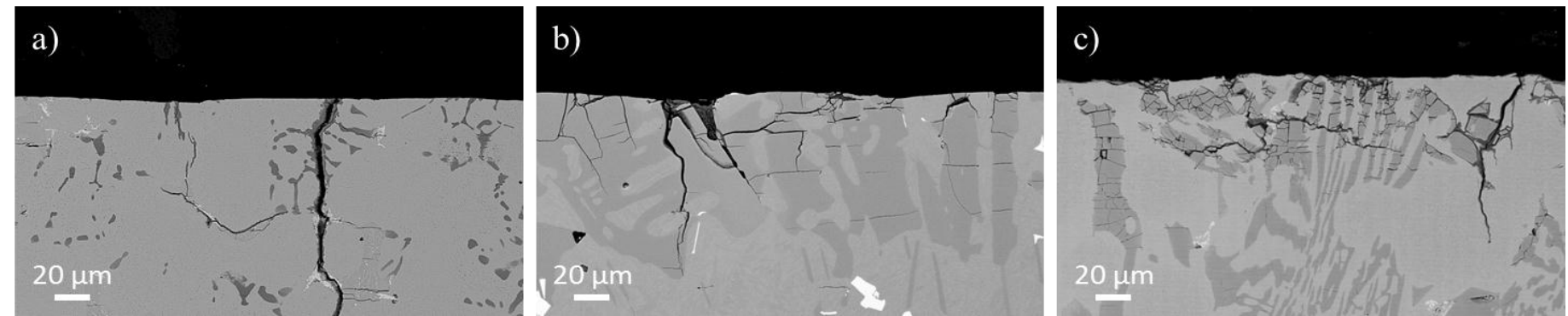

Figure 4: SEM micrographs of polished cross-sections of the worn work roll materials illustrating mechanical and thermal induced cracking of a) $\mathrm{HSS}, \mathrm{b}$ ) $\mathrm{IC}$ and c) $\mathrm{HCr}$. 

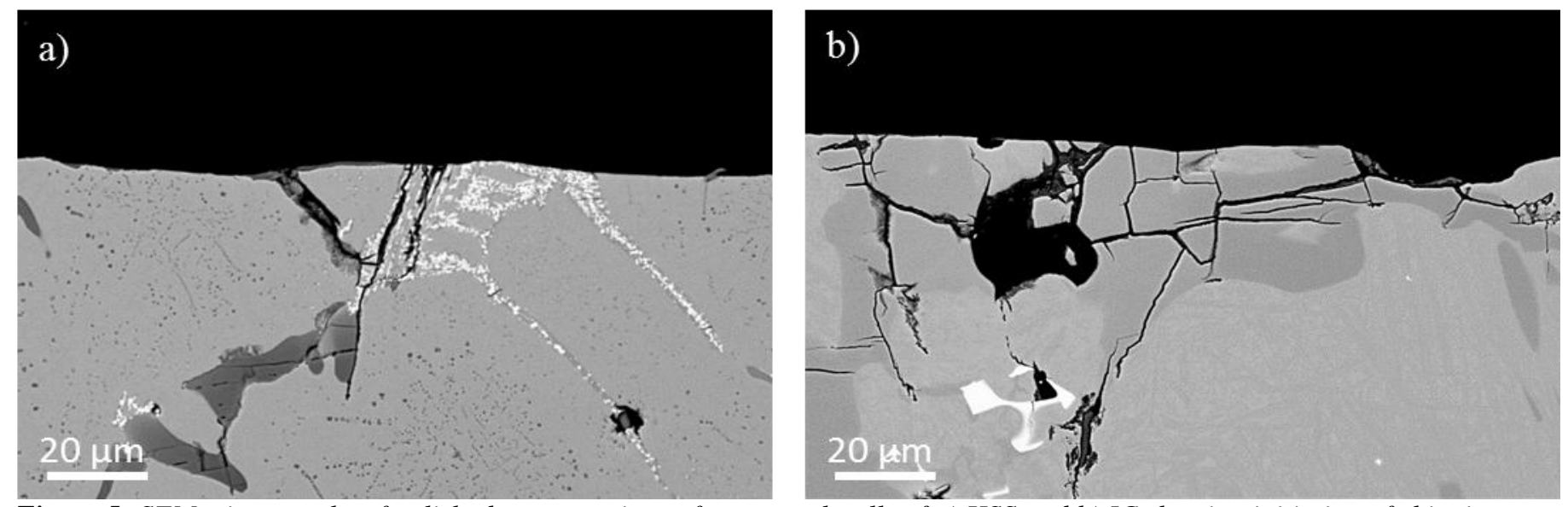

Figure 5: SEM micrographs of polished cross-sections of worn work rolls of a) HSS and b) IC showing initiation of chipping.
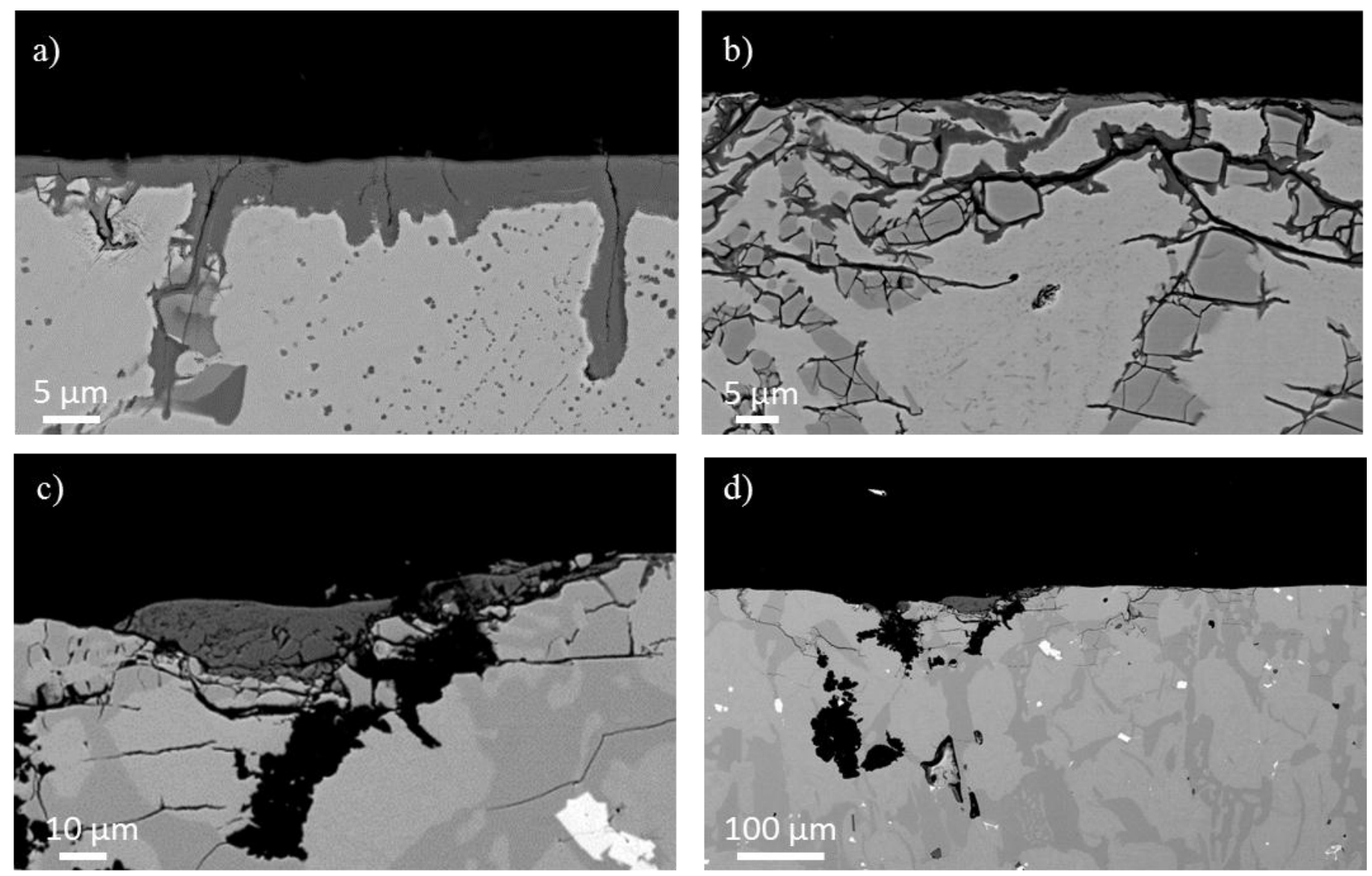

Figure 6: SEM micrographs of polished cross-sections of worn work rolls showing oxide layer formation on a) HSS, b) HCr, c) and d) $I C$.

\section{DISCUSSION}

When comparing the surface characteristics of the different work roll materials it must be kept in mind that the contact conditions differ between the different stands of a hot strip mill, i.e. the maximum temperature is lower while the maximum contact pressure is higher in the later stands than in the early [7]. Thus, the fact that the HSS and HCr work rolls analysed in the present study were all used in the early stands (1-4) while the IC work rolls were used in the late stands (5-6) will naturally influence on the results, e.g. the fact that thermal fatigue cracks dominate for the former work rolls while mechanical fatigue cracks dominate for the latter work rolls.

Despite these differences, the tribological response of the different work roll materials was found to be strongly dependent on the material microstructure and especially the presence and distribution of microstructural constituents, such as the different carbide phases and graphite (in the case of IC). The 
influence of the carbide phases on the tribological performance is complex. The high hardness of the carbides is favourable to the wear resistance but a too high percentage of carbides will increase the cracking and chipping tendency. Also, the presence of carbide networks tends to decrease the fatigue resistance of the microstructure. Consequently, the amount of carbide forming elements as well as the manufacturing process must be controlled in order to obtain an optimised microstructure [2]. The graphite in the IC work roll material may act as a useful lubricant in the hot rolling process [7]. However, the present study shows that graphite rich regions in the close surface area display extensive cracking and consequently the graphite phase may act as a crack initiation site due to its low load carrying capacity.

The oxide layer found on the worn work roll surfaces may be the result of transfer from the strip material as has been seen in other studies [4], the result of oxidation of the work roll material or a combination of these mechanisms. To a certain extent, this oxide may act as a protective layer reducing the wear of the work roll material. However, oxidation within the cracks in the work roll surface may increase the cracking and chipping tendency, thus increasing the wear of the work rolls.

\section{CONCLUSIONS}

A large number of worn work rolls, including High Speed Steel (HSS), Indefinite Chill Iron (IC) and High Chromium Iron $(\mathrm{HCr})$ grades, have been characterised with respect to dominant surface failure mechanisms. The main conclusions can be summarised as follows:

- The surface failure mechanisms of work rolls for hot rolling are very complex involving plastic deformation, abrasive wear, adhesive wear, mechanical and thermal induced cracking, material transfer and oxidation.

- The tribological response of the different work roll materials was found to be strongly dependent on the work roll material microstructure.

- Cracking and chipping of the work roll surfaces, both having a negative impact on work roll wear, are strongly influenced by the presence of carbides, carbide networks and graphite in the work roll surface.

- All worn work roll surfaces show a tendency to work (strip) material pick-up and surface oxidation. EDS-analysis shows that the surface oxide layer generally consists of oxidised work material being transferred to the work roll surface.

\section{ACKNOWLEDGEMENT}

The authors gratefully acknowledge Willy Wolter at Åkers Sweden as well as Magnus Andersson and Birgitta Friberg at SSAB EMEA.

\section{REFERENCES}

1. L. Caithness, S. Cox, S Emery, Surface behaviour of HSS in hot strip mills, in: Proceedings of the Rolls 2000+ Conference, Birmingham, UK, 1999.

2. K. Hwang, S. Lee, H. Lee, Effects of alloying elements on microstructure and fracture properties of cast high speed steel rolls Part I: Microstructural analysis, Materials Science and Engineering A254 (1998) 282-295.

3. J.A. Schey, Tribology in Metalworking, chapter 6.4.5, UMI, USA, 1984

4. L.C. Erickson, S. Hogmark, Analysis of banded hot rolling rolls, Wear 165 (1993) 231-235

5. G. Walmag, X.V. Eyende, M. Sinnaeve, V. Lecomte, Mechanisms of work roll degradation in HSM, in: Proceedings of the 44DG Seminario de Laminacao Processos e Prudutos Laminados e Revestidos, Jordao, Brasil, 2007

6. T. Reip, C. Krempaszky, L. Renhof, E. Werner, Oberflächenschädigung von Walzenkörpern (in German), Mat.-wiss. u. Werkstofftech. 35 (2004) 775-778

7. MNC handbok nr 11, Verktygsstål Snabbstål (in Swedish), MNC, Sweden, 1983

8. F.J. Belzunce, A. Ziadi, C. Rodriguez, Structural integrity of hot strip mill rolling rolls, Engineering Failure Analysis 11 (2004) 789-797

9. T. Nylén, Niobium in cast iron, in: Proceedings of the International Symposium on Niobium 2001, Orlando, USA, 2001, pp. 1063-1080

10.J.W. Park, H.C. Lee, S. Lee, Composition, microstructure, hardness, and wear properties of high-speed steel rolls, Metallurgical and Materials Transaction A 30A (1999) 399-409

11.K.H. Ziehenberger, M. Windhager, State of the art work rolls for hot rolling flat products, in: Proceedings of the CONAC $2007-3^{\text {rd }}$ Steel Industry Conference and Exposition, Monterrey, Mexico, 2007.

12.W.C. Oliver, G.M. Pharr, An improved technique for determining hardness and elastic modulus using load and displacement sensing indentation experiments, J. Mater. Res. 7 (1992) 1564-1583 